\title{
Exatidão de posicionamento de um receptor GPS, operando sob diferentes coberturas vegetais
}

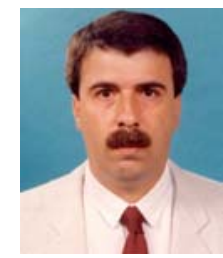

\author{
Rubens Angulo Filho ${ }^{1}$, Carlos A. Vettorazzi1 \& Gabriel A. Sarries ${ }^{2}$ \\ 1 USP/ESALQ. Av. Pádua Dias, 11, CEP 13418-900, Piracicaba, SP. Fone: (19) 3429-4143. E-mail: ruangulo@esalq.usp.br \\ (Foto) e cavettor@esalq.usp.br \\ 2 USP/ESALO. Fone: (19) 3429-4144. E-mail: gabriel@esalq.usp.br
}

Protocolo $128-3 / 9 / 2001$

\begin{abstract}
Resumo: Para avaliar a exatidão de posicionamento planimétrico do receptor GPS Trimble/Pro$\mathrm{XL}$, operando sob diferentes condições de cobertura vegetal (pastagem, seringueira, eucalipto e pinus), o equipamento foi posicionado alternadamente sobre 6 pontos, locados ao acaso nas áreas de estudo, variando o tempo de permanência (1,5 e $10 \mathrm{~min}$ ) mas com a mesma taxa de aquisição de dados (1 s) fazendo-se, posteriormente, a correção diferencial (DGPS) pós-processada dos dados. Os pontos também tiveram suas coordenadas levantadas pelo método topográfico, segundo a NBR 13133 - Execução de Levantamento Topográfico, para fins de comparação. De acordo com o método empregado e os resultados obtidos, foi possível separar as exatidões de posicionamento planimétrico, conforme o tipo de cobertura vegetal, em dois grupos: sem e com cobertura arbórea confirmando, assim, a interferência do dossel na recepção dos sinais emitidos pelos satélites GPS. O aumento do tempo de permanência melhorou a exatidão de posicionamento planimétrico, o que ratifica a escolha da metodologia de levantamento como sendo fundamental para a obtenção de bons resultados de posicionamento.
\end{abstract}

Palavras-chave: sistema de posicionamento global, exatidão, planimetria

\section{Evaluation of the accuracy of positioning a GPS receiver operating under different vegetation covers}

\begin{abstract}
To evaluate planimetric positioning accuracy of a GPS receiver (Trimble/Pro-XL), operating under different conditions of vegetation cover (pasture, rubber trees, eucalyptus and pine trees), 6 control points were located randomly in the study area. For comparison, their coordinates were first obtained by a conventional surveying method, according to NBR 13133 of Brazilian Surveying Standards. Afterwards, the GPS receiver was positioned on those control points, maintaining the acquisition rate of $1 \mathrm{~s}$ while changing the time for 1,5 and $10 \mathrm{~min}$, the DGPS method was used to correct the positioning coordinate data. According to the methodology applied and the results obtained, it was possible to distinguish planimetric positioning accuracy, according to the vegetation cover, in two groups: with and without tree canopy, confirming its interference on the receiver signal reception emitted by the GPS satellites. Increasing the time with the receiver over the control points improved the planimetric positioning accuracy, which emphasizes the importance of appropriate choice of the surveying methodology to be utilized.
\end{abstract}

Key words: global positioning system, accuracy, planimetry

\section{INTRODUÇÃO}

Vários autores têm relatado a aplicação do sistema GPS em atividades relacionadas às áreas agrícola e florestal. Segundo August et al. (1994) especialistas na área ambiental têm utilizado o sistema GPS para o posicionamento das feições levantadas no campo. A exatidão obtida com um equipamento de baixo custo, testado pelos autores, dependeu da metodologia empregada no levantamento. Sob condições ideais de operação,
$95 \%$ dos pontos foram localizados dentro de um raio de $73 \mathrm{~m}$, quando não se procedeu à correção diferencial, e em um raio de $6 \mathrm{~m}$ quando a correção diferencial foi efetuada.

McCormick (1999) conduziu um estudo detalhado da vegetação em 'East Everglades', nos EUA, para mapear com GPS a distribuição de Malaleuca quenervia, uma espécie vegetal exótica e agressiva, marcada para erradicação. O autor conseguiu obter uma exatidão de $94 \%$ no mapeamento, o que permitiu um manejo adequado desta espécie vegetal. 
A mais recente aplicação do sistema GPS na área agrícola, encontra-se na agricultura de precisão. Segundo Stafford (1999) o advento desta nova tecnologia favorece a abertura de um grande mercado potencial para utilização do sistema GPS. Dentro desta linha de trabalho, Balastreire et al. (1997) executaram, com exatidão, o mapeamento da produtividade de milho em uma área de 7,0 ha utilizando, na colhedora, um receptor GPS (marca Trimble, modelo Pro-XL) com posicionamento pelo método de correção diferencial (DGPS) pós-processada e registro das informações.

Na área florestal encontram-se, também, inúmeras aplicações do posicionamento via GPS. Liu \& Brantigan (1995) testaram a exatidão e a eficiência do método diferencial de posicionamento em ambientes florestais e chegaram à conclusão: 1) que a cobertura vegetal e a ondulação do terreno em regiões montanhosas influenciaram na exatidão do posicionamento DGPS; 2) de que, de maneira geral, os resultados obtidos no levantamento estático/DGPS foram mais exatos, mas o trabalho de campo foi menos produtivo quando comparado com os resultados obtidos no levantamento cinemático/DGPS; e 3) de que resultados com baixa exatidão foram obtidos tanto quando foi utilizado o método estático quanto o método cinemático de posicionamento DGPS.

Deckert \& Bolstad (1996) estudaram o desempenho de um equipamento GPS Trimble Pathfinder Professional sob diferentes condições de cobertura florestal e também de relevo, na região leste dos EUA. Suas principais conclusões indicam que a interferência do dossel e do terreno (tipo de relevo) reduz a exatidão e a eficiência do sistema, porque a geometria ótima de satélites no espaço pode não ser visível, mesmo estando acima do horizonte, ou seja, exatidões menores sob PDOP alto.

Segundo Gilbert (1997) os fatores mais importantes que determinam o sucesso de obtenção de valores posicionais com o GPS, sob condições de cobertura vegetal, podem ser enquadrados em três grandes categorias: 1) ambiente; 2) técnicas de coleta de dados; e 3 ) equipamento GPS.

Naesset (1999) utilizando receptores GPS de 6 e 12 canais que captavam os sinais do código $\mathrm{C} / \mathrm{A}$ e das portadoras, avaliou a exatidão de posicionamento de pontos levantados por esses equipamentos, operando sob duas condições de cobertura vegetal: 1) coníferas e 2) árvores com folhas decíduas. A exatidão foi determinada para 38 posições utilizando-se o processamento diferencial dos dados, com recepção só do código C/A e combinação deste código com as portadoras, sendo que o tempo de observação variou entre 2,5 e $30 \mathrm{~min}$. Os resultados obtidos mostraram que: a) com o receptor de 12 canais foi possível obter-se maior exatidão no posicionamento que com o receptor de 6 canais, para todas as condições de trabalho; b) a combinação da observação do código $\mathrm{C} / \mathrm{A}$ e portadora melhorou a exatidão de posicionamento para os dois tipos de equipamento e c) a exatidão melhorou com a melhor distribuição geométrica dos satélites (DOP).

Sigrist et al. (1999) também testaram o impacto de diferentes tipos e densidades de cobertura florestal na coleta de dados, exatidão e precisão de posicionamento GPS, sugerindo, em seu trabalho que, para melhorar a exatidão, deve-se obter pelo menos 300 registros de posicionamento por ponto levantado e, ainda, que o PDOP não é um bom indicador de exatidão de posicionamento quando se trabalha sob florestas.

Assim, com a finalidade de se avaliar o efeito do dossel na recepção dos sinais GPS, testou-se, neste trabalho, o desempenho do receptor GPS Trimble/Pro-XL no levantamento de pontos localizados em áreas com diferentes coberturas vegetais, variando o tempo de permanência sobre esses pontos e se avaliando a exatidão do posicionamento fornecendo, deste modo, subsídio para a sua utilização.

\section{MATERIAL E MÉTODOS}

A área de estudo encontra-se no Campus "Luiz de Queiroz" da Universidade de São Paulo, no município de Piracicaba, SP, cujas coordenadas aproximadas são: a) latitude de $22^{\circ} 42^{\prime} 40^{\prime \prime} \mathrm{S}$ e b) longitude de $47^{\circ} 37^{\prime} 30^{\prime \prime} \mathrm{W}$. A altitude varia entre 500 e 600 $\mathrm{m}$, com o relevo variando de suave ondulado a ondulado.

Para a avaliação do desempenho do equipamento sob diferentes condições de cobertura vegetal, selecionaram-se quatro diferentes áreas: a) pastagem/testemunha; b) Eucalyptus urophylla adulto (plantado em dezembro de 1969) na época da coleta de dados com espaçamento de 2,0 m; c) seringal policlonal, em que os principais clones são RRIM 600, IAN 873, PB 235 e GT 1, com idade variando entre 9 e 13 anos e espaçamento de 7,0 x 3,0 m; e d) Pinus oocarpa (plantado em setembro de 1977). No interior das áreas selecionadas foram locados 6 pontos ao acaso, materializados por meio de piquetes de madeira e identificados por estacas.

Com a finalidade de se obter valores de coordenadas planimétricas considerados testemunhas para os pontos locados nas diferentes áreas, esses pontos foram levantados segundo a NBR 13133 - Execução de Levantamento Topográfico. As poligonais foram da classe IVP, cuja medição angular foi feita pelo método das direções, com uma série de leituras conjugadas direta e inversamente, horizontal e vertical, utilizando-se teodolito classe 2, e a medição linear foi feita com leituras recíprocas (vante e ré) com distanciômetro eletrônico classe 1 e controle taqueométrico com leitura dos três fios. $\mathrm{O}$ equipamento empregado foi o PENTAX / PX-06D (exatidão de $\pm 5 \mathrm{~mm}+5 \mathrm{ppm})$.

De acordo com Gilbert (1997) e Deckert \& Bolstad (1996) que sugerem a obtenção de 60 a 500 registros por ponto e apoiado nas observações de Liu \& Brantigan (1995) decidiuse levantar os pontos por meio do método estático e operar o equipamento com taxa de aquisição constante e igual a $1 \mathrm{~s}$, variando o tempo de permanência sobre os pontos $(1,5 \mathrm{e}$ $10 \mathrm{~min}$ ) nas áreas com os diferentes tipos de cobertura vegetal. Levou-se em consideração, também, o período do dia mais adequado para o levantamento dos pontos com relação ao número de satélites disponíveis e PDOP, sendo que o planejamento da missão para o levantamento dos pontos com o receptor GPS foi feito utilizando-se o software 'Mission Planning'. Os levantamentos dos pontos foram realizados nas seguintes datas: pastagem nos dias 14 e 16 de dezembro; seringueira no dia 17 de dezembro; pinus no dia 18 de dezembro e do eucalipto, nos dias 18 e 21 de dezembro de 1998.

Os dados de campo foram levantados pelo método estático rápido, com o receptor GPS 'Pathfinder Pro XL', previamente 
ajustado para operar com uma taxa de aquisição igual a 1 segundo, $\mathrm{PDOP}<5$ e ângulo de elevação de $15^{\circ}$. Com o auxílio de um bipé, onde foi fixada a antena, os 6 pontos materializados por piquetes e identificados por estacas, localizados nos 4 tipos de cobertura vegetal (pastagem, eucalipto, seringueira e pinus) foram levantados em seqüência (1, 5 e $10 \mathrm{~min})$ e as informações armazenadas no coletor de dados, para posteriormente se fazer a correção diferencial (DGPS).

Terminado o levantamento de campo, os dados armazenados no coletor e os arquivos criados pela 'Pathfinder Community Base Station', foram processados com o auxílio do programa PFINDER.

Para se avaliar a exatidão do equipamento GPS utilizado na determinação das coordenadas planimétricas dos pontos de interesse, foi necessário compará-las com "coordenadas de controle" dos mesmos pontos, determinadas por meio do levantamento topográfico, conforme descrito anteriormente.

As coordenadas de controle e as coordenadas obtidas pelo GPS, estavam em sistemas diferentes e, conseqüentemente, não eram comparáveis. Este problema foi resolvido efetuandose transformações de forma que as coordenadas ficassem todas no mesmo sistema. Para tanto, utilizou-se o programa TDAT, através do qual foram transformadas as coordenadas geográficas fornecidas pelo sistema GPS e referidas ao DATUM WGS-84 para o plano topográfico local $(\mathrm{x}, \mathrm{y})$.

Para se calcular o erro de posicionamento, fez-se uma analogia com o erro linear de fechamento utilizado nos cálculos das poligonais fechadas onde, segundo Domingues (1979) as somas algébricas das projeções $\mathrm{Np}$ ou Ep de uma poligonal fechada, sobre os respectivos eixos $\mathrm{N}$ e E, devem ser nulas (teorema de Carnot). Tem-se, então, o erro de fechamento, definido pelas seguintes expressões:

$$
\begin{gathered}
\varepsilon_{\mathrm{N}}=\Sigma \mathrm{N}_{\mathrm{p}^{+}}-\Sigma \mathrm{N}_{\mathrm{p}^{-}} \\
\varepsilon_{\mathrm{E}}=\Sigma \mathrm{E}_{\mathrm{p}^{+}}-\Sigma \mathrm{E}_{\mathrm{p}^{-}}
\end{gathered}
$$

em que:

$\mathrm{N}_{\mathrm{p}}$ - projeções das coordenadas parciais sobre o eixo $\mathrm{N}$

$E_{p}^{p}$ - projeções das coordenadas parciais sobre o eixo $E$

Assim, de acordo com a teoria dos erros, define-se o erro linear de fechamento, como sendo:

$$
\varepsilon_{\mathrm{L}}=\sqrt{\varepsilon_{\mathrm{N}}^{2}+\varepsilon_{\mathrm{E}}^{2}}
$$

Considerando-se, então, $\Delta \mathrm{x}$ como sendo a diferença entre as coordenadas $\mathrm{x}$ obtidas pelo método topográfico convencional e com o receptor GPS e $\Delta y$, a diferença entre as coordenadas y, o erro de posicionamento será:

$$
\text { Erro de posicionamento }=\sqrt{\Delta \mathrm{x}^{2}+\Delta \mathrm{y}^{2}}
$$

Deste modo, para cada um dos seis pontos localizados sob os 4 tipos diferentes de cobertura vegetal, foram obtidos 3 valores diferentes de erro de posicionamento, referentes aos
3 tempos de permanência utilizados (1, 5 e $10 \mathrm{~min})$. Os pontos foram identificados por letras e números, em que as letras indicavam o tipo de cobertura vegetal, o primeiro número a identificação do ponto e o número seguinte o tempo de permanência com o receptor GPS sobre o ponto (Ex.: Pi35 = ponto $3 \mathrm{da}$ área de pinus com tempo de $5 \mathrm{~min}$; E410= ponto 4 da área de eucalipto, com tempo de $10 \mathrm{~min}$ ).

Para testar a influência da cobertura vegetal e do tempo de medição, na determinação de posição por meio de GPS utilizou-se um delineamento inteiramente ao acaso, modelo de Gauss e Markov (Montgomery, 1993).

A variável de resposta do experimento foi o erro de posicionamento obtido no levantamento por GPS, em relação ao levantamento topográfico convencional.

Os tratamentos principais foram as coberturas vegetais: 1- Pastagem; 2- Seringueira; 3- Pinus e 4- Eucalipto, cada um repetido 6 vezes, constituindo 24 parcelas experimentais, e tomadas medidas da variável resposta, em 3 tempos: 1, 5 e $10 \mathrm{~min}$, totalizando 72 unidades experimentais.

Assim, o modelo matemático adotado foi o de delineamento inteiramente ao acaso, com parcelas subdivididas:

$$
\mathrm{Y}_{\mathrm{ijk}}=\mathrm{m}+\mathrm{C}_{\mathrm{i}}+\mathrm{e}_{\mathrm{ij}}=\mathrm{T}_{\mathrm{k}}=(\mathrm{CT})_{\mathrm{ik}}+\varepsilon_{\mathrm{ijk}}
$$

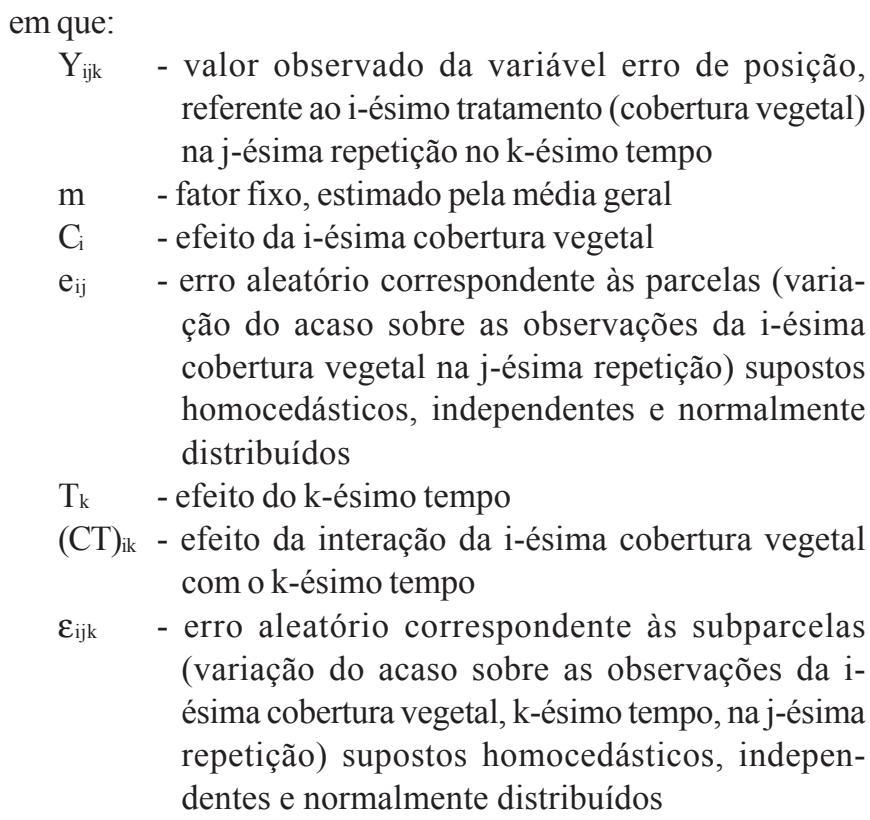

Dado que o fator Cobertura Vegetal é qualitativo, sempre que o teste $\mathrm{F}$ detectou diferença significativa entre suas médias ou entre as médias da interação, fez-se o detalhamento da análise por meio do teste de comparações múltiplas de Tukey e do teste de Dunnett, considerando-se testemunha o nível Pastagem do fator Cobertura Vegetal.

A razão Quadrado Médio (QM) Tratamentos/QM Res. testa as hipóteses:

- $\mathrm{H}_{0}$ : não existe diferença entre as médias de coberturas (QM Coberturas/QM Resíduo (A))

- $\mathrm{H}_{1}$ : não existe diferença entre as médias de tempos de medição (QM Tempos/QM Resíduo (B)) 
- $\mathrm{H}_{2}$ : não há diferença entre as médias da interação de coberturas e tempos de medição (QM Coberturas x Tempos/ QM Resíduo (B))

Para o fator Tempo e suas interações, como se trata de fator quantitativo, a bibliografia consultada recomenda que o detalhamento da análise da variância seja feito por meio de estudo do comportamento da variável (erro de posição) em função do tempo, utilizando-se análise de regressão polinomial e ajuste de curvas. Com base nesse estudo, ajustaram-se os modelos lineares e quadráticos.

Para que os modelos de análise descritos tenham validade e os testes tenham poder, é necessário que sejam satisfeitas as pressuposições:

- homogeneidade de variâncias, ou seja, só podem ser comparados tratamentos com variâncias homogêneas entre si

- independência dos erros

- erros com distribuição normal (ou aproximadamente normal).

Para se testar essas pressuposições, procedeu-se à análise exploratória de dados, por meio de:

- Teste de homogeneidade de variâncias: utilizou-se o teste do $\mathrm{F}_{\text {máx }}$, que consiste em se obter a razão entre a maior e a menor variância de tratamentos e compará-la com um valor tabelado:

$$
\mathrm{F}_{\max }=\frac{\mathrm{S}_{\max }^{2}}{\mathrm{~S}_{\min }^{2}} \sim \mathrm{F}_{(\mathrm{k} \text { trat.; }} \text { v-1 rep.) }
$$

Se o valor obtido for maior que o tabelado, rejeita-se a hipótese de que as variâncias de tratamentos são homogêneas, havendo necessidade de se estudar se essa heterogeneidade pode ou não ser eliminada com uma transformação dos dados; se o valor obtido for menor que o tabelado, não se rejeita a hipótese de homogeneidade de variâncias.

- Análise gráfica dos resíduos: consiste em se plotar, num diagrama de dispersão, os valores estimados pelo modelo da análise da variância versus resíduos padronizados (erro referente a cada observação, dividido pelo desvio padrão amostral). A forma desse gráfico permite detectar-se a falta de independência e existência de heterogeneidade regular (que pode ser eliminada por meio do uso de uma transformação adequada) ou irregular (que não permite transformação, quando se recomenda o uso da estatística não-paramétrica). O intervalo dos resíduos padronizados detecta se há algum(ns) valor(es) desviando-se da normalidade. Normalmente, consideram-se distribuídos os resíduos que estiverem no intervalo de -3 a 3 .

- Diagrama de "ramos e folhas": ordenação dos dados de forma programada para mostrar sua distribuição aproximada, dispersão, assimetria, curtose, agrupamento de valores e, principalmente, detecção de "outliers" (dados discrepantes) e sua localização, alertando para possíveis problemas não notados durante o experimento (p.e., material estranho ao experimento).
Sempre que alguma das pressuposições foi violada, procurou-se a transformação potência adequada (Hoaglin et al., 1983) para a análise paramétrica e se fez, também, a análise não-paramétrica, para comprovação.

\section{RESULTADOS E DISCUSSÃO}

As coordenadas obtidas pelo método topográfico convencional e com GPS, para todos os pontos levantados nas diferentes condições de cobertura vegetal, com os diferentes tempos de permanência e os erros de posicionamento, estão apresentados na Tabela 1 .

Uma análise preliminar dos dados dessas tabelas mostra, como era de se esperar e concordando com Liu \& Brantigan (1995), Deckert \& Bolstad (1996), Naesset (1999) e Sigrist et al. (1999) que os menores erros de posicionamento foram obtidos na área de pastagem, estando eles dentro do esperado, tratando-se de um equipamento da categoria submétrico e confirmando a influência das diferentes coberturas vegetais (seringueira, pinus e eucalipto) no posicionamento planimétrico dos pontos levantados.

Outro aspecto importante foi que, de maneira geral, um tempo maior de permanência sobre os pontos propiciou um erro menor de posicionamento para a maioria dos pontos, independentemente da cobertura vegetal, concordando com Liu \& Brantigan (1995).

Com a finalidade de melhor entender a influência que a cobertura vegetal e o tempo de permanência sobre os pontos levantados tiveram na recepção dos sinais emitidos pelos satélites GPS e, também, se houve diferença entre as vegetações e os tempos escolhidos, procedeu-se à análise estatística dos dados.

\section{Análise exploratória dos dados}

$\mathrm{O}$ valor observado no teste de $\mathrm{F}_{\text {máx }}$, para a variável erro de medição $(157,04)$, foi maior que o tabelado $(29,9)$ a nível de $5 \%$ de significância, com 12 e 5 graus de liberdade, respectivamente, cujo resultado aponta para a presença de heterocedasticidade, ou seja, uma violação importante nas pressuposições do modelo de Gauss e Markov.

A análise gráfica dos resíduos para a variável não transformada e com transformação raiz quadrada, apresentada na Figura 1, permite afirmar-se que as pressuposições de independência (por meio da forma do gráfico), de normalidade (por meio dos intervalos dos resíduos padronizados) não foram violadas e que a pressuposição homogeneidade de variâncias foi restabelecida com a transformação raiz quadrada.

O gráfico de resíduos para a variável transformada através da função raiz quadrada, transformação indicada pela técnica Transformação Potência (Figura 1B) mostra diminuição da heterocedasticidade, porém não a resolução do problema.

A observação dos diagramas de ramos e folhas (Figura 2) permite a identificação de 1 "outlier" para maior na variável não transformada $(3,3)$ correspondente à cobertura eucalipto, no tempo de um minuto. Observa-se, porém, que a ocorrência desse valor não viola as pressuposições para realização da análise da variância do modelo e poder dos testes de comparação. 
Tabela 1. Coordenadas topográficas e GPS e erro de posicionamento para os pontos levantados na área/teste ocupadas por pastagem, seringueira, pinus e eucalipto

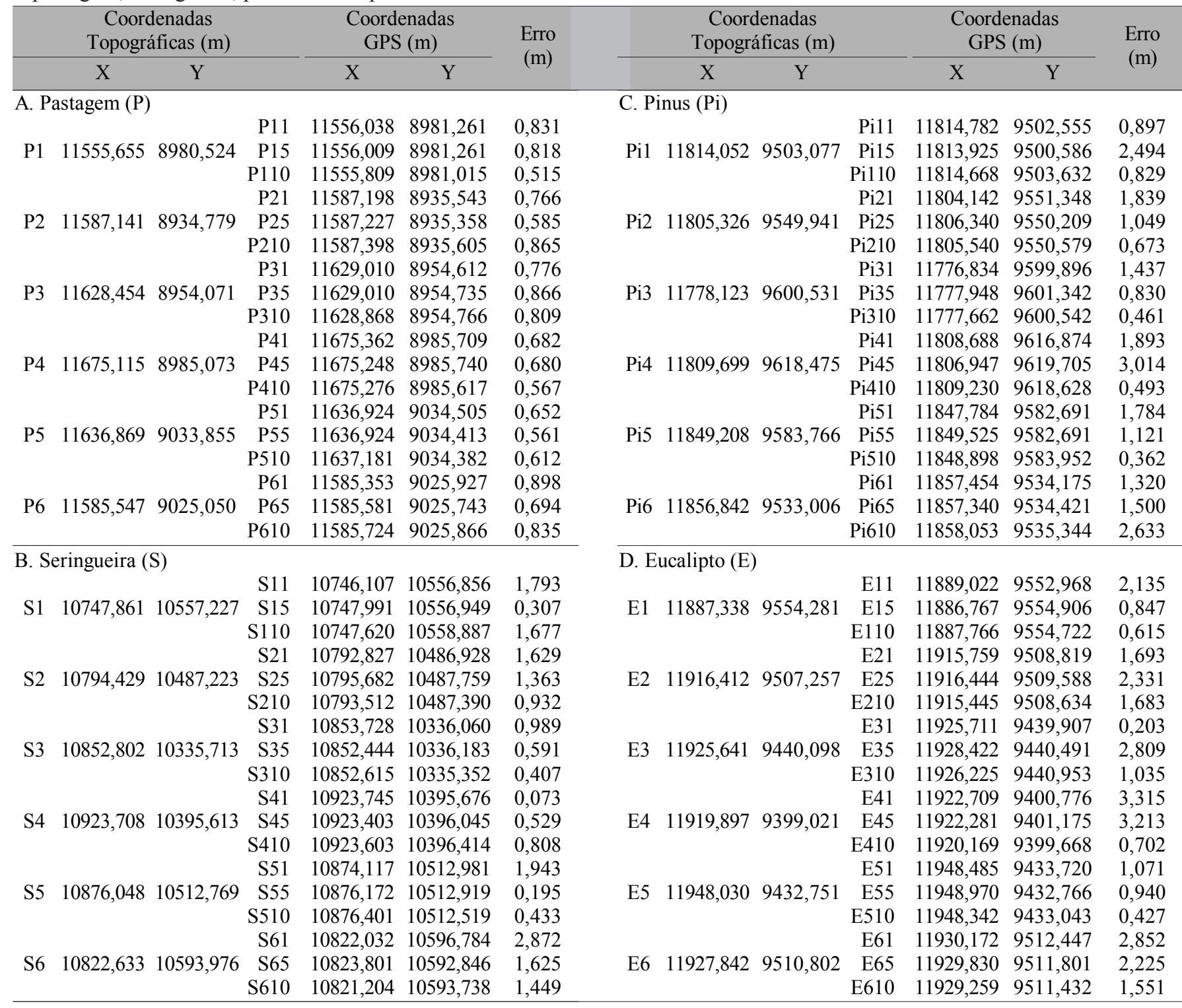

A.

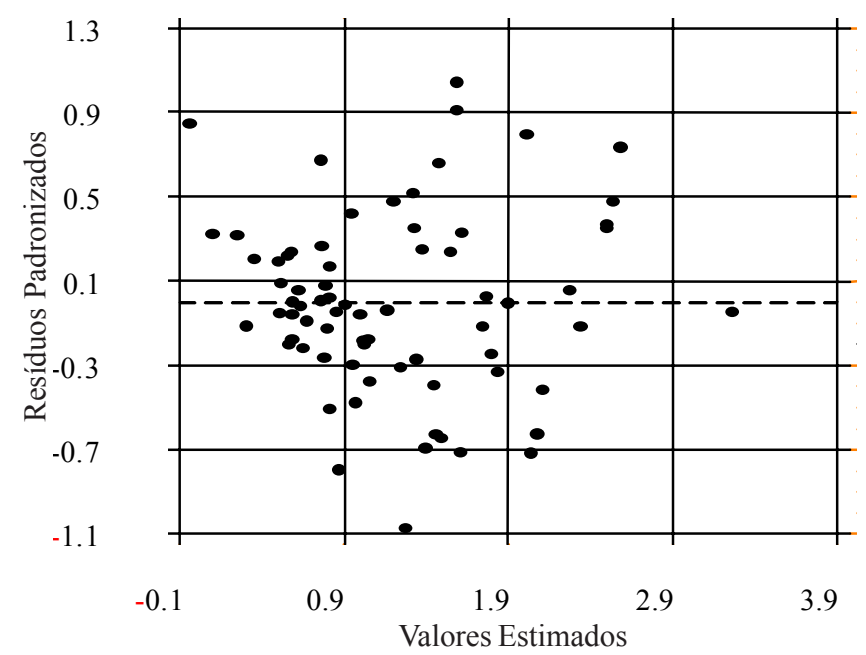

B.

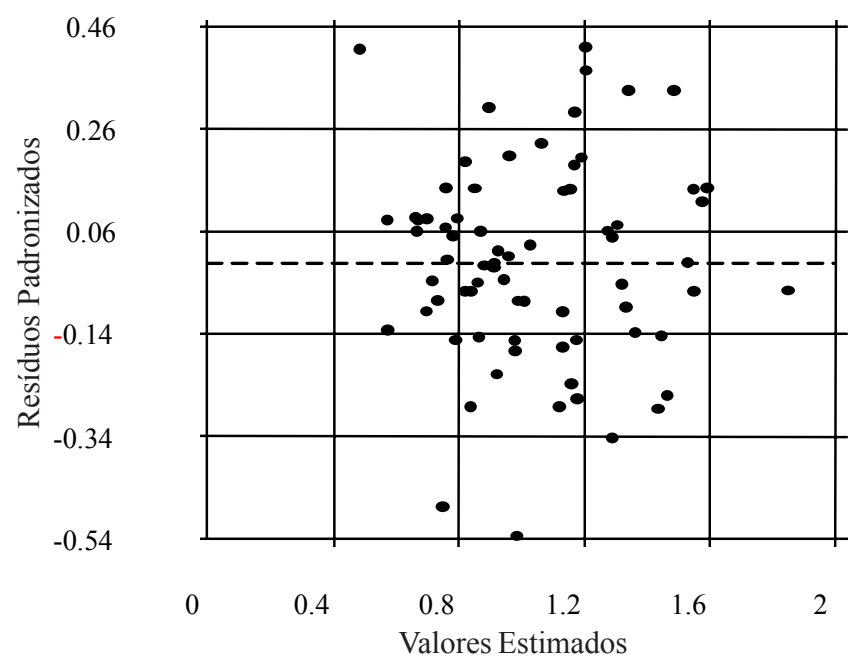

Figura 1. Análise gráfica dos resíduos padronizados para a variável erro de posição, sem transformação (A) e com transformação raiz quadrada $(B)$ 
ANG02.Erro: unit $=0.1 \quad 1 \mid 2$ represents 1.2

\begin{tabular}{ll|l}
10 & $0 *$ & 0123344444 \\
$(31)$ & $0 \circ$ & 5555556666666777888888888888999 \\
31 & $1 *$ & 00013344 \\
23 & 10 & 556666677889 \\
11 & $2 *$ & 1234 \\
7 & 20 & 6888 \\
3 & $3 *$ & 02 \\
& HI & 33
\end{tabular}

SQRT (ANG02.Erro): unit=0.1 $1 \mid 2$ represents 1.2

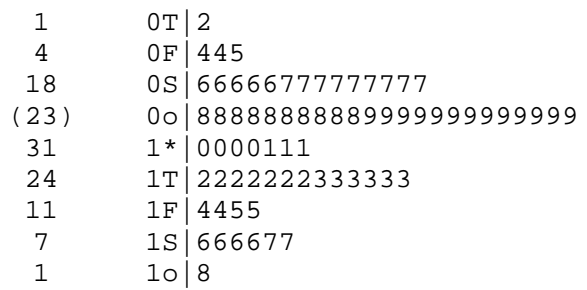

Figura 2. Diagrama de ramos e folhas para a variável erro de posição, sem transformação e com transformação raiz quadrada (* - dígitos primários $0,1,2,3,4{ }^{\circ}$ - dígitos secundários 5,6 , $7,8,9)$

Observa-se também que, no diagrama de ramos e folhas para a variável transformada pela função raiz quadrada, nenhum "outlier" foi observado e a distribuição se mostrou mais simétrica.

\section{Análise da variância e testes de significância}

Análise da variância: Em função da violação da pressuposição de homocedasticidade do modelo de Gauss e Markov adotado, os dados foram analisados aplicando-se a transformação raiz quadrada, recomendada pela aplicação da técnica Transformação Potência e, para confirmação de que a transformação aumentou o poder dos testes, realizou-se também a análise dos dados, por meio de estatística não-paramétrica. Após a aplicação dessas duas técnicas de análise, constata-se que os resultados praticamente não mudam para qualquer uma das duas opções.

A análise da variância para a variável erro de medição, dados transformados com raiz quadrada, encontra-se na Tabela 2.

O quadro de análise da variância, Tabela 2, mostra diferença significativa, pelo teste $\mathrm{F}$, para os fatores cobertura e tempo, com aproximadamente $98 \%$ de confiança. A interação esteve próximo à significância e, nesses casos, recomenda-se o seu desdobramento, ou seja, comparar as coberturas para cada um dos tempos e os tempos em cada uma das coberturas.

Tabela 2. Análise da variância e teste F para a variável erro de medição (com transformação raiz quadrada) em função dos fatores (causas da variação) cobertura e tempo de medição

\begin{tabular}{lrrccc}
\multicolumn{1}{c}{ Causas da } & G.L. & S.Q. & Q.M. & Valor F & PROB.>F \\
\hline Variação & & & & & \\
\hline Cobertura & 3 & 1,4564778 & 0,4854926 & 3,8648 & 0,02449 \\
Resíduo(A) & 20 & 2,5123795 & 0,1256190 & & \\
Parcelas & 23 & 3,9688573 & & & \\
Tempo & 2 & 0,6772253 & 0,3386126 & 4,0644 & 0,02407 \\
COB*TEM & 6 & 0,7673444 & 0,1278907 & 1,5351 & 0,19122 \\
Resíduo (B) & 40 & 3,3324410 & 0,0833110 & & \\
Total & 71 & 8,7458679 & & & \\
\hline
\end{tabular}

Média Geral =1,041881; Coeficiente de Variação $(A)=19,640 \%$; Coeficiente de Variação $(B)=$ $27,703 \%$
Testes de comparação para médias de coberturas vegetais: Os resultados da aplicação do teste de Tukey para todos os tempos e para cada um dos tempos de medição, podem ser observados na Tabela 3 e mostram que, levando-se em consideração todos os tempos, a cobertura eucalipto apresentou a maior média para a variável erro de medição $(1,65 \mathrm{~m})$ diferindo, com $95 \%$ de confiança da cobertura pastagem, que apresentou a menor média $(0,72 \mathrm{~m})$. Esta foi a única diferença estatisticamente significativa detectada. Quando se consideraram as médias de cobertura em todos os tempos, observou-se que, embora apresentando a maior média, o eucalipto somente diferiu estatisticamente da pastagem.

Tabela 3. Comparações entre coberturas vegetais pelo teste de Tukey, baseadas em médias da variável erro de posicionamento

\begin{tabular}{lcccc}
\hline $\begin{array}{l}\text { Cobertura } \\
\text { Vegetal }\end{array}$ & \multicolumn{3}{c}{ Tempo de Medição (min) } & Média Geral \\
\cline { 2 - 4 } (todos os tempos)
\end{tabular}

Obs.: Médias seguidas por alguma letra em comum não diferem pelo Teste de Tukey a nível de $95 \%$ de confiança (letras minúsculas) ou $99 \%$ de confiança (letras maiúsculas)

Na mesma Tabela 3 observou-se o comportamento das coberturas vegetais nos diferentes tempos de medição.

Confirmando o resultado da análise da variância, observase que o teste de Tukey não detectou diferença significativa entre as médias de cobertura dentro de tempos, exceção feita, a nível de $5 \%$, para coberturas, dentro do tempo de $5 \mathrm{~min}$, onde o eucalipto foi significativamente superior à pastagem e à seringueira e igual ao pinus. O pinus, por sua vez, não diferiu estatisticamente da maior média nem das menores.

Um outro teste de significância aplicado ao fator cobertura vegetal foi o de Dunnett, recomendado para comparações de tratamentos com uma testemunha, sendo a pastagem considerada testemunha (Tabela 4). As conclusões não mudaram substancialmente em relação ao teste de Tukey, porém surgiram novas diferenças, pelo fato do teste de Dunnett ser mais sensível que o de Tukey, para comparações com testemunha.

Nas comparações das médias do fator cobertura, para todos os tempos, foi evidenciada, pelo teste de Dunnett, diferença significativa entre pastagem e pinus, a nível de $95 \%$ de confiança, enquanto pelo teste de Tukey elas foram consideradas iguais. Entre pastagem e eucalipto, que pelo teste de Tukey apresentavam diferença com $95 \%$ de confiança, pelo teste de Dunnett evidenciou-se diferença com $99 \%$ de confiança.

Tabela 4. Comparações entre coberturas vegetais pelo teste de Dunnett em médias da variável erro de medição, considerando-se pastagem como testemunha

\begin{tabular}{llllc}
\hline \multicolumn{1}{c}{$\begin{array}{c}\text { Cobertura } \\
\text { Vegetal }\end{array}$} & \multicolumn{2}{c}{ Tempo de Medição (min) } & Média Geral \\
\cline { 2 - 4 } (todos os tempos)
\end{tabular}

Obs.: Médias seguidas por “*” diferem significativamente em relação à pastagem (Testemunha), pelo teste de Dunnett com $95 \%$ de confiança, na primeira coluna após a média, e $99 \%$ na segunda. A sigla "ns" indica que não existem diferenças significativas 
Quando se estudaram as coberturas dentro dos tempos, observou-se que pelo teste de Dunnett foi evidenciada diferença entre a pastagem e o eucalipto, com $95 \%$ de confiança no tempo de 1 min (pelo Tukey não foi detectada diferença entre eles). Dentro de $5 \mathrm{~min}$ do fator tempo ocorreu diferença entre pastagem e pinus com $95 \%$ de confiança (pelo Tukey não houve diferença entre eles) e entre pastagem e eucalipto uma diferença com $99 \%$ de confiança (pelo Tukey a confiança dessa diferença era de $95 \%$ ). Aos 10 min, o teste de Dunnett foi concordante com o teste de Tukey, isto é, não foi detectada diferença entre pasto e demais coberturas vegetais.

\section{Detalhamento da análise para tempos de medição, por meio da análise de regressão polinomial}

O estudo dos tempos para todas as coberturas vegetais mostrou tendência linear decrescente, altamente significativa (com mais de $99 \%$ de confiança) relacionando o fator tempo de medição (x) com a variável de resposta erro de posição (y) mediante a seguinte equação:

$$
y=-0,0609 x+1,532 \quad\left(R^{2}=0,9506\right)
$$

Quando se desdobraram os graus de liberdade da interação para visualizar a tendência do fator tempo dentro de cada cobertura vegetal observou-se, para todas as coberturas, tendência linear decrescente, com confiança de $96 \%$ para o pinus, $95 \%$ para o eucalipto e sem significância estatística para a pastagem e para a seringueira. Na Figura 3 são apresentadas essas tendências, as retas ajustadas e os coeficientes de determinação.

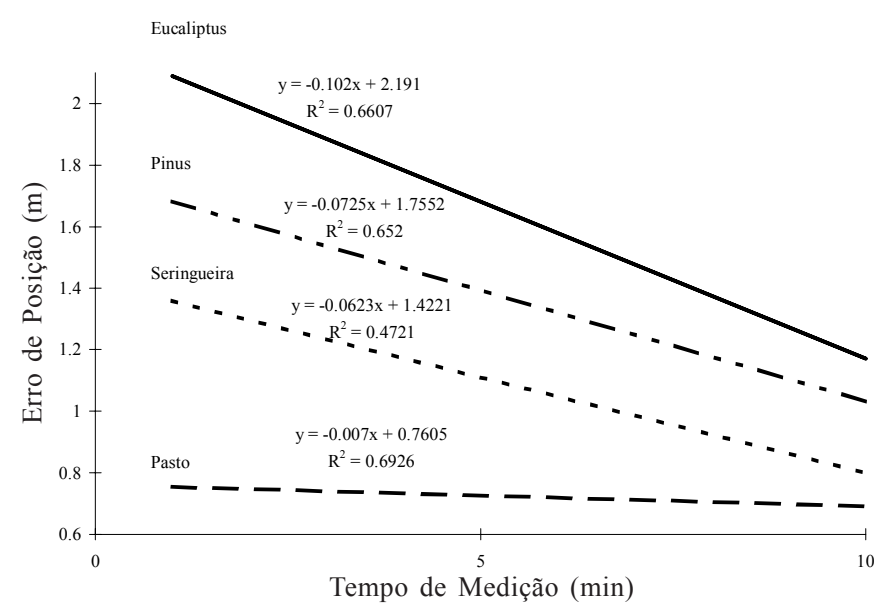

Figura 3. Ajuste da relação entre o fator tempo de medição e a variável de resposta erro de posicionamento, para cada uma das coberturas vegetais

O gráfico de tendências para cada uma das coberturas vegetais mostra que, aumentando-se o tempo de medição, o erro de posição tende a confluir com o erro obtido para a pastagem (testemunha). Nesses gráficos pode-se visualizar, também, uma tendência, a ocorrência de maiores erros de posicionamento para o eucalipto, seguido do pinus, seringueira e pastagem, com um máximo de diferenças para o tempo de medição de 1 min e mínimo para 10 min.

Apesar da análise estatística mostrar diferenças no erro de posicionamento em apenas algumas situações, Tabelas 4 e 5, observa-se que o tempo de permanência de $10 \mathrm{~min}$ foi o que apresentou melhores resultados, independentemente do tipo de cobertura vegetal e que, portanto, dentro da metodologia empregada, seria o tempo de permanência recomendado. Esses resultados mostram que a escolha do método de levantamento GPS é fundamental para a obtenção de bons resultados, o que concorda com as observações feitas por Liu \& Brantigan (1995), Gilbert (1997), Naesset (1999) e Sigrist et al. (1999).

\section{CONCLUSÕES}

De acordo com a metodologia empregada e os resultados obtidos, as principais conclusões foram:

1. Foi possível separar-se as exatidões de posicionamento planimétrico conforme o tipo de cobertura vegetal, em dois grupos: sem e com cobertura arbórea, confirmando a interferência do dossel na recepção dos sinais emitidos pelos satélites GPS.

2. De maneira geral, o aumento do tempo de permanência melhorou a exatidão de posicionamento planimétrico, o que ratifica a escolha da metodologia de levantamento como fundamental para a obtenção de bons resultados de posicionamento.

\section{LITERATURA CITADA}

August, P.; Michaud, J.; Labash, C.; Smith, C. GPS for environmental applications - Accuracy and precision of locational data. Photogrammetric Engineering and Remote Sensing, Bethesda, v.60, n.1, p.41-45, 1994.

Balastreire, L.A.; Elias, A.I.; Amaral, J.R. Agricultura de precisão: mapeamento da produtividade da cultura do milho. Engenharia Rural, Piracicaba, v.8, n.1, p.97-111, 1997.

Deckert, C.; Bolstad, P.V. Forest canopy, terrain, and distance effects on global positioning system point accuracy. Photogrammetric Engineering and Remote Sensing, Bethesda, v.62, n.30, p.317-321, 1996.

Domingues, F.A.A. Topografia e astronomia de posição: para engenheiros e arquitetos. São Paulo: Editora Mc Graw Hill do Brasil, 1979. 403p.

Gilbert, C. GPS - Performance sob coberturas vegetais. Fator GIS, Curitiba, v.5, n.18, p.52-53, 1997.

Hoaglin, D.C.; Mosteller, F.; Tukey, J.W. Análise exploratória de dados:técnicas robustas. Lisboa: John Wiley \& Sons, 1983. 446p.

Liu, C.J.; Brantigan, R.D. Using differential GPS for forest traverse surveys. Canadian Journal of Forest Research, Ottawa, v.25, n.11, p.1795-1805, 1995.

McCormick, C.M. Mapping exotic vegetation in the Everglades from large-scale aerial photographs. Photogrammetric Engineering and Remote Sensing, Bethesda, v.65, n.2, p.179-184, 1999.

Montgomery, D.C. Design and analysis of experiments. New York: John Wiley \& Sons. 1993. 578p.

Naesset, E. Point accuracy of combined pseudorange and carrier phase differential GPS under forest canopy. Canadian Journal of Forest Research, Ottawa, v.29, n.5, p.547-553, 1999.

Sigrist, P.; Coppin, P.; Hermy, M. Impact of forest canopy on quality and accuracy of GPS measurements. International Journal of Remote Sensing, London, v.20, n.18, p.3595-3610, 1999.

Stafford, J.V. GPS in agriculture - A growing market! Journal of Navigation, New York, v.52, n.1, p.60-69, 1999. 